\title{
Simultaneous Estimation of Aliskiren and Amlodipine in Combined Tablet Formulation by Simultaneous Equation and First Derivative Spectroscopic Methods
}

\author{
Yadav $\mathbf{N}^{1 *}$ and Goyal $\mathrm{A}^{2}$ \\ ${ }^{1}$ Department of Pharmacy, SRMSCET, India \\ ${ }^{2} B$ N Institute of Pharmaceutical Sciences, India
}

Submission: March 14, 2018; Published: March 27, 2018

"Corresponding author: Nita Yadav, Department of Pharmacy, SRMSCET, Bareilly, Uttar Pradesh, India; Tel: +919458702598, Email: raj_neetu78@rediffmail.com

\begin{abstract}
Simple, sensitive and accurate UV-spectroscopic methods were developed and validated for simultaneous estimation of aliskiren and amlodipine in tablet formulation using simultaneous equation and first derivative spectroscopic methods. Developed methods include direct estimation of amlodipine at $365 \mathrm{~nm}$ without any interference, since aliskiren has zero absorbance at this wavelength. Estimation of aliskiren through simultaneous equation was performed at $279 \mathrm{~nm}$, while $236.8 \mathrm{~nm}$ were selected as zero crossing point for estimation of aliskiren by first order derivative spectroscopic method. Linearity was found to be satisfactory over the concentration range of $25-300 \mu \mathrm{g} / \mathrm{ml}$ and $5-100 \mu \mathrm{g} / \mathrm{ml}$ for aliskiren and amlodipine respectively. The mean percentage label claim of aliskiren and amlodipine using simultaneous equation was 99.84 and $99.85 \%$ respectively, while for first derivative spectroscopic method it was found to be 100.36 and $99.85 \%$ respectively. The developed methods are economical and reproducible for routine analysis of aliskiren and amlodipine in tablet formulation.
\end{abstract}

Keywords : Aliskiren; Amlodipine; First order derivative method; Simultaneous equation Method; Validation

\section{Introduction}

Chemically aliskiren (ALS) is (2S, 4S, 5S, 7S)-5-Amino-N-(3amino-2, 2-dimethyl-3-oxopropyl)-4-hydroxy-7-[[4-methoxy3-(3-methoxypropoxy)phenyl]methyl]-8-methyl-2-propan-2ylnonanamide [1]. It is a is a white to slightly yellowish crystalline powder. Aliskiren is the first in a class of drugs called direct renin inhibitors. It is used for essential (primary) hypertension [2]. It is highly soluble in water, ethanol and DMSO $[3,4]$. Amlodipine (AML) is chemically 3-Ethyl-5-methyl $( \pm)-2-[(2$-aminoethoxy) methyl]-4-(2- chlorophenyl)-1, 4-dihydro-6-methyl-3,5pyridinedicarboxylate. Amlodipine besylate is white to off white powder, crystalline and has long-acting 1, 4-dihydropyridine calcium channel blocker $[5,6]$. It acts primarily on vascular smooth muscle cells by stabilizing voltage-gated L-type calcium channels in their inactive conformation. By inhibiting the influx of calcium in smooth muscle cells, amlodipine prevents calcium-dependent myocyte contraction and vasoconstriction. Amlodipine is used to treat hypertension and chronic stable angina $[7,8]$. Several analytical methods have been reported for estimation of ALS and its combination with other drugs which includes spectrophotometry and HPLC [9-13]. Similarly, various spectrophotometric and HPLC methods have been reported for estimation of AML and its combination with other drugs [1418]. In the present work, a successful attempt has been made to estimate both these drugs simultaneously using dual wavelength UV spectrophotometric method. Structures of both the drugs ALS and AML are given in (Figures $1 \& 2$ ).

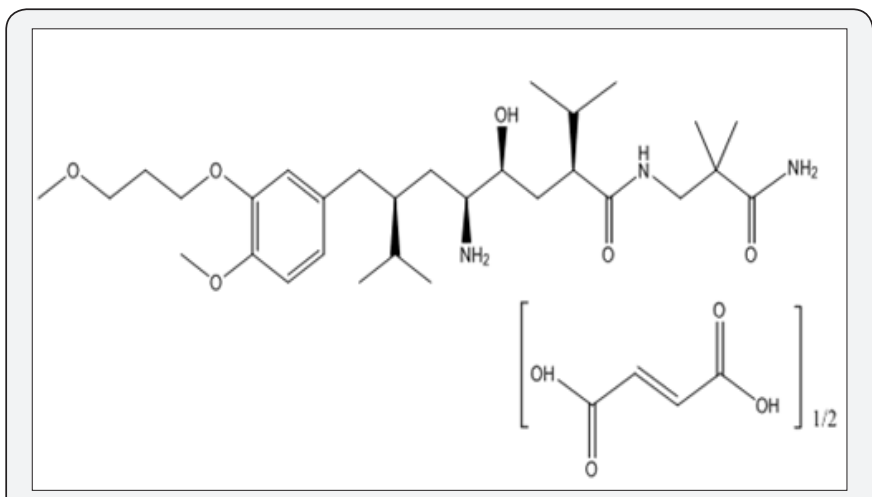

Figure 1: Structure of Aliskiren hemifumarate. 


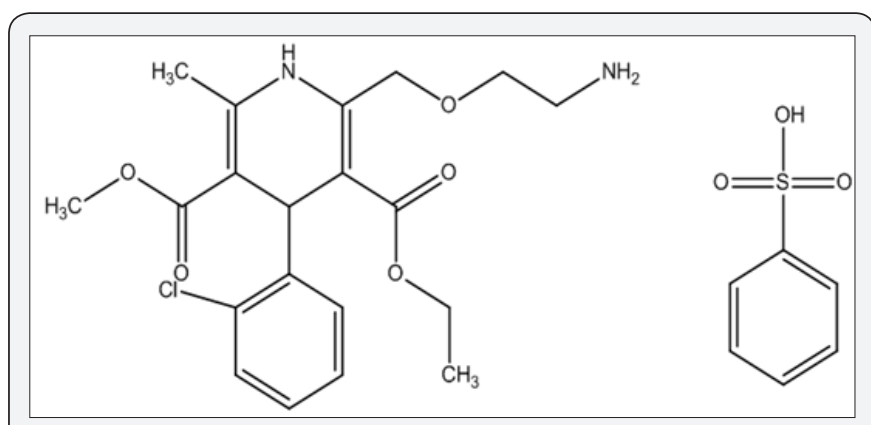

Figure 2: Structure of Amlodipine besylate.

\section{Materials and Methods}

\section{Instrumentation}

A double beam UV spectrophotometer (UV-1800, Shimadzu, Japan) with UV probe software version (2.31) and $10 \mathrm{~mm}$ quartz cells was used. All weights were taken on an electronic balance (Schimadzu-220h).

\section{Reagents and Chemicals}

Pure drug, Aliskiren hemifumarate and amlodipine besylate was procured from Swapnroop Drugs and Pharmaceuticals, Aurangabad, Maharashtra, India. Marketed formulation was procured from local Pharmacy. All the chemicals and reagents used were of A.R. grade.

\section{Method Development}

Preparation of Standard Stock Solution: The standard stock solutions of Aliskiren and Amlodipine were prepared by dissolving $110.5 \mathrm{mg}$ of aliskiren hemifumarate $1110.5 \mathrm{mg}$ of aliskiren hemifumarate is equivalent to $100 \mathrm{mg}$ of aliskiren) and by dissolving pure drug of amlodipine besylate equivalent to $100 \mathrm{mg}$ of amlodipine in separate $100 \mathrm{~mL}$ volumetric flask containing sufficient quantity of distilled water, the solutions were sonicated for $5 \mathrm{~min}$ then volume was made up to the mark with distilled water to get a concentration of $1000 \mu \mathrm{g} / \mathrm{mL}$ of each solution. The standard stock solutions were further diluted to obtain desired concentrations.

Preparation of Sample Solution: Twenty tablets were weighed and powdered. The quantity of the powder equivalent to $150 \mathrm{mg}$ of ALS was transferred to $100 \mathrm{ml}$ volumetric flask. The content was mixed with sufficient quantity of distilled water and sonicated for $20 \mathrm{~min}$ to dissolve the drug. The solution was then filtered through a Whatman filter paper no. 41 and made up to the mark with distilled water. An aliquot of solution $(1.0 \mathrm{ml})$ was transferred to a $10 \mathrm{ml}$ volumetric flask and the volume was adjusted up to the mark with distilled water to obtain required concentration of ALS $(150 \mu \mathrm{g} / \mathrm{ml})$ and AML $(10 \mu \mathrm{g} / \mathrm{ml})$.

\section{Simultaneous Equation Method}

For simultaneous estimation of ALS and AML using simultaneous equation method (SE method) the solutions of ALS $(50 \mu \mathrm{g} / \mathrm{ml})$ and AML $(20 \mu \mathrm{g} / \mathrm{ml})$ were prepared from the standard stock solutions of ALS and AML and scanned over the range of $200 \mathrm{~nm}$ to $400 \mathrm{~nm}$. An overlain spectrum was studied for development of suitable method for analysis. The overlain spectrum of ALS and AML is shown in (Figure 3). From the overlay spectra, $279 \mathrm{~nm}$ wave length was selected for the estimation of ALS using simultaneous equation method. Estimation of AML was done as a single component at $365 \mathrm{~nm}$. The absorptivity values were calculated and were applied in framed simultaneous equation 1 , which is presented as,]

$$
A=a x_{1} C_{X}+a y_{1} C_{Y}=0.0060 C_{X}+0.0034 C_{Y}
$$

Where, $A$ is absorbance of sample solution at $279 \mathrm{~nm}, \mathrm{C}_{X}$ and $\mathrm{C}_{\mathrm{Y}}$ are concentrations of ALS and AML, respectively in $\mu \mathrm{g} / \mathrm{ml}$.

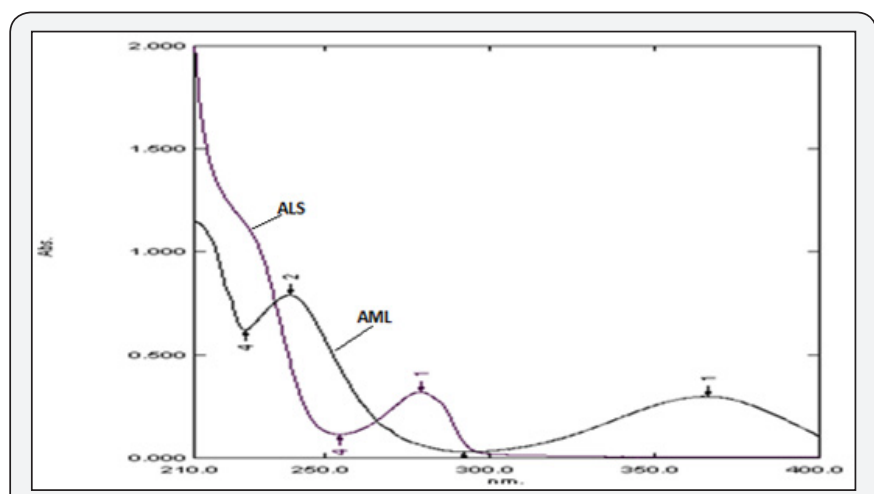

Figure 3 : Overlain spectrum of Aliskiren and Amlodipine.

\section{First Order Derivative Method}

Estimation of AML was performed similarly as in simultaneous equation method. For estimation of ALS first order derivative method (DR method) was applied. The zero order spectrum was then derivatised to obtain first order derivative spectrum (Figure 4). From this spectrum of ALS and AML zero crossing point of $236.8 \mathrm{~nm}$ was selected using $2 \mathrm{~nm}$ as wavelength interval $(\Delta \lambda=$ 2) and scaling factor taken as 1 for estimation of ALS.

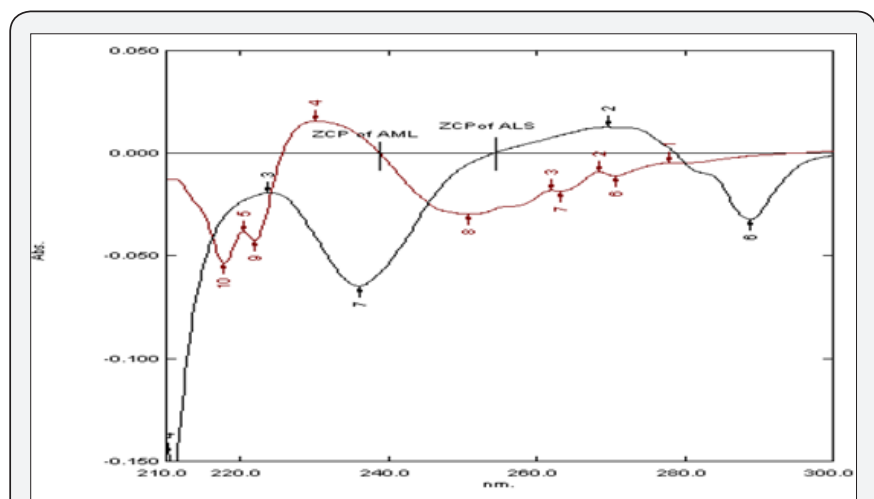

Figure 4 : Overlain first order derivative spectra of Aliskiren and Amlodipine.

\section{Analysis of ALS \& AML in Tablet Formulation}

The absorbance of final sample solution was measured against distilled water as blank at $279 \mathrm{~nm}$ for SE method and at 236.8nm for DR method while the estimation of AML was done 
directly at $365 \mathrm{~nm}$. The analysis procedure was repeated five times for marketed formulation.

\section{Method Validation}

Linearity and Range: Aliquots of standard solution of ALS $(0.25,0.5,0.75,1.0,1.25,1.5,2.0$ and $3.0 \mathrm{ml})$ and AML $(0.05$, $0.1,0.2,0.3,0.4,0.5,0.6$ and $1.0 \mathrm{~mL}$ ) were transferred in a series of $10 \mathrm{ml}$ volumetric flasks. The volume was adjusted up to the mark with distilled water and mixed. Absorbance values were recorded at $279 \mathrm{~nm}$ for SE method and at $236.8 \mathrm{~nm}$ for DR method against distilled water as blank for determination of ALS. Absorbance values of AML were recorded at $365 \mathrm{~nm}$ for all dilutions. The calibration curves were plotted between the concentration of component and absorbance values of ALS for SE method and between concentration and $\mathrm{dA} / \mathrm{d} \lambda$ for DR method. Calibration curve for AML was plotted between the concentration of component and absorbance value of AML.

Standardization of the Method by Analysis of Mixed Standard Solutions: To check the validity of the selected methods, mixed standard solutions of ALS and AML were prepared. The solutions were subjected to determine absorbance values at respective wavelengths and concentration of the components were calculated.

Accuracy: The accuracy of the method was determined for both the methods by calculating recoveries of ALS and AML by the standard addition method. Known amount of standard solution of ALS and AML were added at $80 \%, 100 \%$ and $120 \%$ levels to pre-quantified tablet sample solutions of ALS and AML. The results are reported in terms of \% Recovery.

\section{Results and Discussion}

\section{Method Development and Validation}

Two simple, sensitive and accurate UV-spectroscopic methods were developed and validated for simultaneous estimation of aliskiren and amlodipine in tablet formulation using SE and DR spectroscopic methods. From the overlain spectra of the drugs it was observed that SE and DR spectroscopic methods were suitable methods for simultaneous determination of ALS and AML. Distilled water was taken as solvent system, as both the drugs were soluble in this solvent and reduce the cost of the method. In SE method and DR method, wavelengths 279 $\mathrm{nm}$ and $236.8 \mathrm{~nm}$ respectively were selected for determination of ALS, whereas AML was estimated directly at $365 \mathrm{~nm}$ as ALS has zero absorbance at this wavelength. Optimized method parameters for simultaneous equation and first order derivative spectroscopic methods are shown in Table 1.

\section{Linearity}

The calibration curves of ALS and AML were linear in the range of $25-300 \mu \mathrm{g} / \mathrm{ml}$ and $5-100 \mu \mathrm{g} / \mathrm{ml}$ respectively. Regression equation and $R^{2}$ values are given in (Table 1 ).

Table 1: Optimized method parameters for simultaneous equation and first derivative spectroscopic methods.

\begin{tabular}{|c|c|c|}
\hline Method parameters & \multicolumn{2}{|c|}{ Optimized parameters } \\
\hline Method & SE Method & DR Method \\
\hline Solvent & Distilled water & $210-400 \mathrm{~nm}$ \\
\hline Scanning range & $210-400 \mathrm{~nm}$ & $236.8 \mathrm{~nm}$ \\
\hline Analytical wavelength for determination of ALS & $279 \mathrm{~nm}$ & $365 \mathrm{~nm}$ \\
\hline Analytical wavelength for determination of AML & $365 \mathrm{~nm}$ & $25-300 \mu \mathrm{g} / \mathrm{ml}$ \\
\hline Linearity range for ALS & $25-300 \mu \mathrm{g} / \mathrm{ml}$ & $5-100 \mu \mathrm{g} / \mathrm{ml}$ \\
\hline Linearity range for AML & $5-100 \mu \mathrm{g} / \mathrm{ml}$ & 0.999 \\
\hline Regression equation $\left(\mathrm{y}=\mathrm{mx}+\mathrm{c}\right.$ ) and $\mathrm{R}^{2}$ value for ALS & $0.006 \mathrm{x}+0.002$ & 0.999 \\
\hline Regression equation $\left(\mathrm{y}=\mathrm{mx}+\mathrm{c}\right.$ ) and $\mathrm{R}^{2}$ value for AML & $0.014 \mathrm{x}+0.003$ & \\
\hline
\end{tabular}

\section{Standardization of the method by analysis of mixed standard solutions}

The concentration of ALS and AML recovered from mixed standard solutions for both methods was within range and are given in Table 2.

\section{Accuracy}

The percentage recoveries of drugs from sample were determined by standard addition of pure drugs at three known concentrations and recoveries were obtained at each level.
The percent recoveries for ALS were found to be in the range of 100.26- $100.40 \%$ for SE method and 99.94-100.45 \% for DR method. Percent recoveries for AML were found to be in the range of $99.62-100.13 \%$ for both methods. The results of accuracy studies are shown in Table 3.

\section{Application of the Method in Assay of Tablets}

The proposed UV method was applied for the determination of ALS and AML in their combined pharmaceutical formulation and the results are shown in Table 4. 
Table 2: Results of validation studies of Aliskiren and Amlodipine using mixed standards.

\begin{tabular}{|c|c|c|c|c|c|c|c|c|c|c|}
\hline \multirow{3}{*}{ S. No. } & \multirow{2}{*}{\multicolumn{2}{|c|}{$\begin{array}{l}\text { Amount Present } \\
(\mu \mathrm{g} / \mathrm{ml})\end{array}$}} & \multicolumn{4}{|c|}{ Amount Found (SE Method) } & \multicolumn{4}{|c|}{ Amount Found (DR Method) } \\
\hline & & & \multicolumn{2}{|c|}{$(\mu \mathrm{g} / \mathrm{ml})$} & \multicolumn{2}{|c|}{$\%$} & \multicolumn{2}{|c|}{$(\mu \mathrm{g} / \mathrm{ml})$} & \multicolumn{2}{|c|}{$\%$} \\
\hline & ALS & AML & ALS & AML & ALS & AML & ALS & AML & ALS & AML \\
\hline 1 & 25 & 60 & 25.09 & 60.79 & 100.39 & 101.31 & 25.09 & 60.79 & 100.36 & 101.31 \\
\hline 2 & 50 & 50 & 49.57 & 50.64 & 99.14 & 101.29 & 50.54 & 50.64 & 101.09 & 101.29 \\
\hline 3 & 75 & 40 & 75.15 & 40.29 & 100.21 & 100.71 & 75.09 & 40.29 & 100.12 & 100.71 \\
\hline 4 & 100 & 30 & 99.26 & 29.93 & 99.26 & 99.76 & 100.54 & 29.93 & 100.54 & 99.76 \\
\hline 5 & 125 & 20 & 125.92 & 20.29 & 100.73 & 101.43 & 125.09 & 20.29 & 100.07 & 101.43 \\
\hline 6 & 150 & 10 & 150.35 & 9.93 & 100.23 & 99.29 & 149.63 & 9.93 & 99.75 & 99.29 \\
\hline
\end{tabular}

Table 3: Results of accuracy study for Aliskiren and Amlodipine.

\begin{tabular}{|c|c|c|c|c|c|}
\hline \multirow{2}{*}{ Drugs } & \multirow{2}{*}{ AccuracyLevel (\%) } & \multicolumn{2}{|c|}{ Recovery (\%)* } & \multicolumn{2}{c|}{ \% RSD } \\
\cline { 3 - 6 } & & SE Method & DR Method & SE Method & DR Method \\
\hline ALS & 80 & $100.28 \pm 0.35$ & $100.30 \pm 0.66$ & 0.35 & 0.65 \\
\hline & 100 & $100.40 \pm 0.40$ & $99.94 \pm 0.52$ & 0.40 & 0.53 \\
\hline AML & 120 & $100.26 \pm 0.26$ & $100.45 \pm 0.76$ & 0.26 & 0.75 \\
\hline & 80 & $99.62 \pm 0.77$ & $99.62 \pm 0.77$ & 0.78 & 0.62 \\
\hline
\end{tabular}

*Mean \pm SD ( $n=3)$, SD (Standard deviation), \%RSD (Percent relative standard deviation).

Table 4: Analysis of Formulation of Aliskiren and Amlodipine.

\begin{tabular}{|c|c|c|c|c|c|c|c|}
\hline \multirow{2}{*}{ Drugs } & Label Claim & \multicolumn{2}{|c|}{ Amount Found (mg/tab) } & \multicolumn{2}{c|}{ Label Claim (\%)* } & \multicolumn{2}{c|}{ RSD (\%) } \\
\cline { 2 - 8 } & (mg/tab) & SE Method & DR Method & SE Method & DR Method & SE Method & DR Method \\
\hline ALS & 150 & $149.76 \pm 0.68$ & $150.55 \pm 1.44$ & $99.84 \pm 0.45$ & $100.36 \pm 0.96$ & 0.45 & 0.95 \\
\hline AML & 10 & $9.99 \pm 0.12$ & $9.99 \pm 0.12$ & $99.86 \pm 1.17$ & $99.86 \pm 1.17$ & 1.18 & 1.18 \\
\hline
\end{tabular}

*Mean \pm SD ( $n=5)$, SD (Standard deviation), \% RSD (Percent relative standard deviation).

\section{Conclusion}

The proposed simultaneous equation method and first order derivative gives accurate and precise results for determination of aliskiren and amlodipine in marketed formulation (tablet) without prior separation and is easily applied for routine analysis. Method validation has been demonstrated by variety of tests like linearity, accuracy and validation through mixed standard. The proposed method can be successfully applied for determination of these drugs in commercial tablet formulation.

\section{Acknowledgement}

The authors express their sincere gratitude to Swapnroop Drugs and Pharmaceuticals, Aurangabad, Maharashtra, India for providing the pure drug samples of Aliskiren Hemifumarate and Amlodipine Besylate and are also thankful to colleagues and authorities of Department of Pharmacy, SRMSCET, Bareilly, U.P. who helped us in this work.

\section{References}

1. Lam S, Choy M (2007) Aliskiren: an oral renin inhibitor for the treatment of hypertension. Cardiol Rev 15(6): 316-312.
2. Schmieder RE (2006) The effect of angiotensin-converting-enzyme inhibition on diabetic nephropathy. J Renin Angiotensin Aldosterone Syst 7: S16.

3. Daugherty KK (2008) Aliskiren-A review. Am J Health-Syst Pharm 65: 13-23.

4. Pranay Wal, Ankita Wal, Awani KR, Dixit A (2011) Aliskiren: An orally active rennin inhibitor. J Pharm Bioallied Sci 3(2): 189-193.

5. Triggle DJ (2007) Calcium channel antagonists: clinical uses-past, present and future. Biochem Pharmacol 74(1): 1-9.

6. Taylor SH (1994) Usefulness of amlodipine for angina pectoris. Am J Cardiol 73(3): 28A-33A.

7. Abernethy DR (1992) Pharmacokinetics and pharmacodynamics of amlodipine. Cardiology 80(1): 31-36.

8. Hermida RC, Ayala DE, Mojon A (2008) Chronotherapy with nifedipine GITS in hypertensive patients: improved efficacy and safety with bedtime dosing. Am J Hypertens 21(8): 948-954.

9. Babu KS, Rao JVLNS, Vijaya K (2011) Simple and sensitive method for the determination of aliskiren hemifumarate using hplc-uv detection. J of Chemistry 4(2): 285-288.

10. Wrasse-Sangoi M, Sangoi MS, Oliveira PR, Secretti LT, Rolim CMB (2011) Determination of Aliskiren in Tablet Dosage Forms by a Validated Stability-indicating RP-LC Method. J Chromatogr Sci 49(2):170-175. 
11. Sangoi WM, Leonardo TS, Isabel FD, Clarice M, Bueno R (2010) Development and validation of an UV spectrophotometric method for the determination of aliskiren in tablets. Quim Nova 33(6): 1330-1334.

12. Ezzeldin MI, Shokry E, Fouad MA, Elbagary RI (2013) Application of chromatographic and spectrophotometric methods for the analysis of selected antihypertensive combinations. Inter J of Analyt Pharma \& Biomed Sci 2(3): 6-15.

13. Sangoi MDS, Wrasse-Sangoi M, Oliveira PRD, Todeschini V, Rolim CMB (2011) Simultaneous determination of aliskiren and hydrochlorothiazide from their pharmaceutical formulations by monolithic silica HPLC column employing experimental designs. J of Liquid Chromatogr \& Related Technol 34(17): 1102-1112.

14. Zarghi A, Foroutan SM, Shafaati A, Khoddam A (2005) Validated HPLC method for determination of amlodipine in human plasma and its application to pharmacokinetic studies. Farmaco 60(9): 789-792.
15. Runja CP, Ravikumar, Srinivasa RA (2014) A Validated Stability Indicating RP-HPLC Method Development and Validation for Simultaneous Estimation of Aliskiren Hemifumarate and Amlodipine Besylate in Pharmaceutical Dosage Form. Chromatogr Res Int p. 1-7.

16. Patel S, Patel Ch (2013) Development and validation of absorbance correction method for simultaneous estimation of aliskiren and amlodipine in combined dosage form. Asian J Pharmaceut Res Health Care 5(2): 2-43.

17. Chaitanya KK, Gowri SD, Samson ID (2013) RP-HPLC method development and validation of amlodipine and losartan in binary mixture. J of Global Trends in Pharma Sci 4(3): 1144-1152.

18. Mehulkumar P, Ramesh V, Kumar V, Srinivas R, Diwan PV (2009) Simultaneous Spectroscopic Estimation of Amlodipine Besylate And Olmesartan Medoximil In Tablet Dosage Form. Asian J Res Chem 2(2): 127-130. 